\title{
AKTIVITAS PEMBERIAN KREDIT KOMERSIL PADA BANK NAGARI CABANG SIJUNJUNG
}

\author{
Sepni Maiwati, Ratna Widayati \\ Akademi Keuangan dan Perbankan Padang \\ ratnawidayati@akbpstie.ac.id
}

\begin{abstract}
The purpose of this study was to determine the activity of commercial lending at Bank Nagari Sijunjung Branch. In this study the authors use the method of collecting the data in two ways: Collection Method DataStudi Library (Library Research) This research was conducted by studying books, papers, articles, reading reports and publications related to the object of research, Field Study (Field Research) research directly carried out at Nagari Bank Branch Sijunjung to obtain the necessary data and conducting interviews for primary data. From the discussion above, the writer can draw conclusions as follows: Activity granting commercial loans at Bank Nagari Branch Sijunjung implemented according to the procedure of loans comprising the loan application, credit analysis, a signatory to the contract credit agreement, loan disbursements (disbursement), and credit control made for the smooth repayment of the loan so that any problems that arise can be immediately recognized and can immediately find a way out. The development of commercial loans in 2014 through 2016, which increased as the type of multi-use working capital loans increased from year to year is $33.9 \%$ to $50.7 \%$ and $90.3 \%$. Caused because the number of requests from borrowers who want to develop their business or facilitate the business activities being undertaken by the debtor
\end{abstract}

Keywords: commercial loans

\section{LATAR BELAKANG}

Perbankan menempati posisi yang strategis dalam pembangunan dari perekonomian serta pembagian pendapatan dalam masyarakat. Bank merupakan perusahaan yang bergerak di bidang keuangan. Aktifitas perbankan yang pertama adalah menghimpun dana dari masyarakat luas dalam bentuk simpanan atau yang biasa dikenal dengan istilah funding. 
Setelah memperoleh dana dalam bentuk simpanan dari masyarakat, maka Bank tersebut akan menyalurkan kembali dananya kepada masyarakat dalam bentuk pinjaman atau yang lebih di kenal dengan istilah kredit. Dalam pemberian kredit dikenakan bunga, bank juga mengenakan jasa pinjaman kepada penerima kredit dalam bentuk biaya administrasi serta biaya provisi dan komisi.

Peranan perbankan dalam menghimpun dan menyalurkan dana masyarakat perlu ditingkatkan dengan lebih memperhatikan pembiayaan kegiatan sektor perekonomian nasional dengan prioritas kepada koperasi, pengusaha kecil dan menengah, serta berbagai lapisan masyarakat tanpa mendiskriminasi, sehingga akan memperkuat struktur perekonomian nasional. Dalam rangka meningkatkan kemajuan perekonomian rakyat menegah golongan kebawah Bank Nagari mempunyai peranan yang sangat besar dalam kemajuan usaha - usaha rakyat yang tersebar diseluruh wilayah Indonesia. Pemberian kredit kepada kelompok menengah kebawah diharapkan dapat meningkatkan pendapatan dan kesempatan kerja.

Aktivitas pemberian kredit ini diharapkan dapat memberikan kontribusi pendapatan terbesar bagi Bank Nagari Cabang Sijunjung. Sehubungan dengan hal tersebut maka Bank Nagari Cabang Sijunjung dalam memberikan kredit harus dengan prinsip kehati - hatian. Salah satu kredit yang diberikan Bank Nagari Cabang Sijunjung adalah kredit komersil.

Berdasarkan uraian diatas penulis tertarik menuangkan dalam penelitian yang berjudul "Aktivitas Pemberian Kredit Komersil Pada Bank Nagari Cabang Sijunjung"

Rumusan Masalah

Berdasarkan latar belakang diatas maka rumusan masalahnya adalah bagaimana aktivitas pemberian kredit komersil pada Bank Nagari Cabang Sijunjung.

\section{METODE ANALISA DATA}

Dalam menganalisa data penulis menggunakan analisis data kualitatif. Data yang diperoleh kemudian dirangkum dengan hasil wawancara dan dokumen lainnya, untuk mengetahui aktivitas pemberian kredit komersil pada Bank Nagari Cabang Sijunjung.

\section{Metode Penelitian}

\section{MetodePengumpulan Data}

Penulisan ini mengunakan metode pengumpulan data sebagai berikut :

a. Studi kepustakaan (Library/Research)

Penelitian yang dilakukan dengan membaca beberapa buku - buku ilmiah dan tulisan - tulisan yang berhubungan dengan pembahasan yang dilakukan.

b. Studi Lapangan (Fiel Research)

Peninjauan langsung untuk meneliti hasil data primer, ini akan dapat membantu penulis untuk melengkapi data yang diperlukan .adapun cara riset lapangan ini adalah dengan mewawancarai pihak - pihak yang berkepentingan dalam hal ini adalah perusahaan atau instansi terkait. 


\section{HASIL DAN PEMBAHASAN \\ Pengertian Bank}

Bank didefenisikan oleh undang undang no 10 tahun 1998 tentang perubahan atas UU no 7 tahun 1992 pasal 1 tentang perbankan adalah badan usaha yang menghimpun dana dari masyarakat dalam bentuk simpanan dan menyalurkan kepada masyarakat dalam bentuk kredit dan atau bentuk bentuk lainnya dalam rangka meningkatkan taraf hidup rakyat banyak.

\section{Pengertian Kredit}

Menurut Komaruddin Sastra Dipoera pengertian kredit adalah penyediaan uang atau tagihan (yang disamakan dengan uang) berdasarkan kesepakatan pinjam - meminjam antara bank dan pihak lain yang dalam hal ini peminjam berkewajiban melunasi kewajibannya setelah jangka waktu tertentu dengan sejumlah bunga yang ditetapkan terlebih dahulu.

\section{Unsur - unsur kredit}

Menurut Thomas suyanto unsur - unsur yang terdapat dalam pemberian kredit adalah sebagai berikut :

1. Kepercayaan (trust) adalah sesuatu yang paling utama dari unsur kredit yang harus ada.

2. Waktu (time) adalah bagian yang paling sering dijadikan kajian oleh pihak analis finance khususnya oleh analis kredit.

3. Risiko disini menyangkut persoalan seperti degree of risk. Disni yang paling dikaji adalah pada keadaan yang terburuk yaitu pada saat kredit tersebut tidak kembali atau timbulnya kredit macet.

4. Prestasi adalah prestasi yang dimiliki oleh kreditur untuk pemberian kepada debitur.

\section{Tujuan, Fungsi dan manfaat kredit}

Dalam kehidupan perekonomian dan perdagangan, tujuan fungsi dan manfaat kredit menurut Irham Fahmi (2014 : 48) adalah sebagai berikut :

1. Tujuan kredit

a. Mendapatkan keuntungan

b. Membantu usaha nasabah

c. Membantu pemerintah

2. Fungsi Kredit

a. Untuk berusaha memposisikan uang sebagai alat pertukaran yang efektif.

b. Sebagai penyalur dana dan pembina bagi dunia usaha.

c. Sebagai pengawas moneter.

d. Sebagai bagian untuk menghindari pemusatan financial.

e. Untuk menciptakan suatu pemerataan pendapatan.

f. Sebagai salah satu alat untuk menggairahkan bisnis internasional.

g. Untuk meninggaktkan aktifitas penggunaan barang dan jasa.

h. Pendorong dan pencipta stabilitas ekonomi..

3. Manfaat kredit

a. Bagi debitur.

1) Meningkatkan usahanya dengan pengadaan berbagai factor produksi.

2) Kredit bank relatife mudah diperoleh bila usaha debitur layak dibiayai. 
3) Dengan jumlah yang banyak memudahkan calon debitur memilih bank yang cocok dengan usahanya.

4) Bermacam - macam jenis kredit dapat disesuaikan calon debitur.

5) Rahasia keuangan debitur terlindungi.

b. Bagi bank

1) Bank memperoleh pendapatan dari bunga yang diterima dari debitur.

2) Dengan adanya bunga kredit diharapkan rentabiitas bank akan membaik dan perolehan laba meningkat.

3) Dengan pembemberian kredit akan membantu dalam pemasaran produk atau jasa perbankan lainnya.

4) Pemberian kredit untuk merebut pangsa pasar dalam industri perbankan.

5) Pemberian kredit untuk mempertahankan dan mengembangkan usaha bank.

c. Bagi pemerintah

1) Alat untuk memicu pertumbuhan ekonomi secara umum.

2) Alat untuk mengendalian kegiatan moneter.

3) Alat untuk mencitptakan lapangan usaha.

4) Meningkatkan pendapatan Negara.

5) Menciptakan dan memperluas pasar.

d. Bagi masyarakat

1) Mendorong pertumbuhan dan perluasan ekonomi.

2) Mengiringi tingkat pengangguran.

3) Meningkatkan pendapatan masyarakat.

4) Memberikan rasa aman bagi masyarakat yang menyimpan uangnya dibank.

\section{Prinsip - prinsip kredit}

Menurut Irham Fahmi (2014 : 15) analisis 5C adalah sebagai berikut:

a. Character

Character atau watak debitur sangat menentukan kemauan untuk membayar kembali kredit yang telah diterimanya.

b. Capacity

Capacity mengandung arti kemampuan calon debitur dalam mengelola usahanya.

c. Capital

Informasi mengenai besar kecilnya modal (capital) perusahaan calon debitur adalah sangat penting bagi bank.

d. Collateral (jaminan kredit) merupakan setiap aktiva atau barang-barang yang diserahkan debitur sebagai jaminan atas kredit yang diperoleh dari bank.

e. Conditions of ekonomi

Yang dimaksud conditions disini adalah keadaan perekonomian secara umum dimana perusahaan tersebut beroperasi.

Sedangkan penilaian suatu kredit dapat pula dilakukan dengan analisis 7P, menurut Kasmir (2009 : 97) adalah sebagai berikut : 


\section{Personality}

Yaitu menilai nasabah dari segi kepribadiannya atau tingkah lakunya seharihari maupun kepribadiaannya di masa lalu.

\section{Party}

Yaitu mengklasifikasikan nasabah ke dalam klasifikasi atau golongangolongan tertentu berdasarkan modal, loyalitas, serta karakternya sehingga nasabah dapat digolongkan ke golongan tertentu dan akan mendapatkan fasilitas kredit yang berbeda pula dari bank.

\section{Perpose}

Yaitu mengetahui tujuan nasabah dalam mengambil kredit termasuk jenis kredit yang diinginkan nasabah.

4. Prospect

Yaitu untuk menilai usaha nasabah di masa yang akan datang apakah menguntungkan atau tidak dengan kata lain mempunyai prospek atau sebaliknya.

\section{Payment}

Merupakan ukuran bagaimana cara nasabah mengembalikan kredit yang telah diambil atau dari sumber mana saja dana untuk pengembalian kredit.

6. Profitabillity

Untuk menganalisis bagaimana kemampuan nasabah dalam mencari laba.

\section{Protection}

Tujuannya adalah bagaimana menjaga agar kredit yang diberikan mendapatkan jaminan perlindungan, sehingga kredit yang diberikan benarbenar aman.

Aktivitas pemberian kredit komersil pada Bank Nagari Cabang Sijunjung, memiliki prosedur pemberian kredit yang merupakan langkah - langkah atau suatu proses dilakukan secara bertahap dan berhati - hati agar kredit yang disalurkan dapat berjalan dengan lancar dan kembali tepat waktu, tepat jumlah dan berhasil guna bagi kedua belah pihak yaitu pihak bank dan pihak debitur.

Bank Nagari Cabang Sijunjung terpaku dalam prinsip 5C yaitu:

a. Character (karakteristik)

Penilaian ini berdasarkan reputasi calon debitur dan latar belakang atas pengalaman calon debitur dalam memenuhi kewajibannya terhadap Bank Nagari Cabang Sijunjung, selain itu pemohon tidak termasuk dalam daftar hitam atau black list yang artiya calon debitur tidak pernah terdaftar kredit macet pada bank lain.

b. Capacity (kemampuan)

Penilaian ini diutamakan pada kemampuan calon debitur untuk dapat membayar angsuran yang telah ditetapkan Bank Nagari Cabang Sijunjung dengan jangka waktu yang telah disepakati.

c. Capital (modal)

Penilaian atas modal yang disetor dapat berupa uang muka yang diberikan oleh debitur atau pemohon kepada Bank Nagari Cabang Sijunjung. 


\section{d. Collateral (jaminan)}

Pada umumnya setiap aktifitas pemberian kredit diperlukan suatu agunan, agunan yang ada pada Bank Nagari Cabang Sijunjung dapat berupa BPKP, Sertifikat rumah, Sertifikat tanah dan lain - lain. Agunan digunakan sebagai sumber pembayaran kembali kredit jika debitur mengalami kesulitan dalam memenuhi kewajibannya dikemudian hari.

e. Condition of economi

Penilaian ini di titik beratkan pada kondisi atau keadaan politik, social, ekonomi, dan budaya yang akan mempengaruhi pada suatu saat maupun untuk kurun waktu tertentu yang kemungkinan dapat mempengaruhi kelancaran pengembalian kredit yang telah diberikan kepada debitur.

Dalam tahap ini juga diadakan penilaian tentang keadaan usaha atau badan usaha yang mengajukan permohonan kredit. Penilaian tersebut meliputi berbagai aspek yaitu :

a. Aspek managemet dan organisasi (management \& organization)

Pada dasarnya calon debitur hendaknya merupakan seorang yang berjiwa wiraswata dan mempunyai keahlian yang cukup tentang bidang usahanya.

b. Aspek pemasaran marketing (marketing)

Barang atau jasa yang dihasilkannya atau diperdagangkan nya harus mempunyai prospek pemasaran yang baik, baik dilihat dari segi konsumen menurut jumlahnya maupun penebaran daerahnya.

c. Aspek teknis (technical)

Peralatan atau teknologi yang digunakan baik kapasitas maupun jenisnya serta proses produksinya, hendaknya efektif dan efesien dalam arti masih memberikan keuntungan yang cukup bagi perusahaannya.

d. Aspek keuangan (financial)

Dari perhitungan keuangan perusahaan tercermin adanya kemampuan dari perusahaan calon debitur untuk memenuhi kewajiban - kewajibannya, baik untuk pengembalian pokok pinjaman maupun bunganya.

e. Aspek yuridis/hukum (legal)

Usaha yang akan diberi bantuan kredit harus memenuhi ketentuan - ketentuan hukum yang berlaku termasuk bentuk hukum debitur, lengkapnya surat - surat izin dan surat bukti jaminan/agunan yang diperlukan, serta cara - cara pengikatan jaminan atau agunan.

f. Aspek social ekonomi (cocial and economic)

Usaha yang akan dibiayai oleh kkredit bank tersebut hendaknya dapat menerap tenaga kerja yang selama ini menganggur dan sedapat mungkin tidak merusak atau mengganggu keadaan lingkungan hidup (pencemaran) ditinggal dari analisis mengenai dampak atas lingkungan hidup (AMDAL).

Dengan prinsip 5C dan penilaian berbagai aspek Bank Nagari Cabang Sijunjung juga melakukan survey ke lapangan atau on the spot untuk mendatangi lokasi calon debitur dan melakukan analisa secara langsung. Bank nagari Cabang Sijunjung juga melakukan wawancara dengan pihak pihak lain yang mengetahui karakter dan usaha calon debitur. 
Setelah melakukan kunjungan ke lapangan dan melakukan wawancara, kemudian Account Officer (AO) membuat kelayakan kredit yang berisi kondisi usaha calon debitur secara keseluruhan yang meliputi berbagai aspek untuk mengambil Keputusan kredit. Dalam hal ini adalah menentukan apakah kredit akan diberikan atau di tolak, jika di terima maka di persiapkan adminitrasinya dan melakukan penandatangan akad kredit / perjanjian. Keputusan kredit merupakan keputusan team, begitu pula bagi kredit yang di tolak, maka hendaknya di kirim surat penolakan sesuai dengan alasan masingmasing.

2. Penandatangan akad kredit / perjanjian lainya

Kegiatan ini merupakan kelanjutan dari keputusan kredit, maka sebelum kredit dicairkan akan terlebih dahulu calon nasabah menandatangani akad kredit, mengikat jaminan dengan surat perjanjian atau pernyataan yang di anggap perlu.

3. Realisasi kredit

Realisasi kredit di berikan setelah penandatangan surat - surat yang di perlukan dengan membuka rekening giro atau tabungan di bank yang bersangkutan, dapat di ambil sesuai dengan ketentuan dan tujuan kredit.

4. Pengawasan kredit

Demi kelancaran pengembalian pinjaman tersebut, maka Account Officer (AO) harus melakukan monitoring kepada nasabah secara berkala, sehingga setiap permasalahan yang akan timbul dapat segera diketahui dan bisa dengan segera dicari jalan keluarnya. Dalam pemberian pinjaman hal - hal yang diterapkan adalah:

a. Pemberian kredit diprioritaskan kepada nasabah tabungan sehingga pihak bank lebih mudah dalam mengontrol pengembaliannya melalui arus kas dan karakter dari nasabah sudah diketahui terlebih dahulu.

b. Pihak bank harus lebih berhati - hati dalam melihat karakter nasabah serta melihat prospek usaha yang akan dibiayai karena tingkat persaingan pasar yang ketat.

c. Dalam pengelolaan pemberian kredit selain menggunakana prinsip 5C harus juga diperhatikan prinsip 3T yaitu tepat waktu, tepat jumlah, tepat guna tampa mengabaikan prinsip kehati - hatian.

d. Harus dilakukan monitoring secara lanjut dan berkala, sehingga memperkecil resiko kerugian bagi kedua bela pihak. 


\section{Perkembangan kredit komersil}

Pada Bank Nagari Cabang Sijunjung perkembangan kredit komersil dapat dilhat sebagai berikut :

Tabel 1

perkembangan kredit komersil dalam bentuk persentase (\%)

\begin{tabular}{|l|c|c|c|}
\hline \multirow{2}{*}{ Jenis kredit } & \multicolumn{3}{|c|}{ Tahun } \\
\cline { 2 - 4 } & $\mathbf{2 0 1 4}$ & $\mathbf{2 0 1 5}$ & $\mathbf{2 0 1 6}$ \\
\hline Kredit modal kerja multiguna & $33,9 \%$ & $50,7 \%$ & $90,3 \%$ \\
\hline Kredit investasi multi guna & $40,9 \%$ & $41,3 \%$ & $55,7 \%$ \\
\hline Kredit Rekening Koran & $30,8 \%$ & $26,8 \%$ & $21,7 \%$ \\
\hline Kredit Usaha Mikro Kecil & $45,7 \%$ & $53,9 \%$ & $49,2 \%$ \\
\hline
\end{tabular}

Sumber : Bank Nagari Cabang Sijunjung

Dari data tabel diatas menunjukan bahwa kredit komersil pada tahun 2014 sampai 2016 terus mengalami kemajuan, tetapi dilihat dari kredit rekening Koran terjadi penurunan permintaan kredit dari $30,8 \%$ menjadi $21,7 \%$ dan pada kredit usaha mikro kecil terjadi fluktuasi dari tahun ketahun, pada tahun 2015 mengalami kenaikan dari tahun 2014 yaitu sebesar 45,7\% menjadi 53,9\% akan tetapi pada tahun 2016 mengalami penurunan sebesar 49,2\%.

cara penyelesaian Kredit bermasalah

Dari tabel dibawah ini dapat dilihat kolektibitas kredit bermasalah pada Bank Nagari Cabang Sijunjung

Tabel 2

Kolektibilitas kredit bermasalah berdasarkan presentase (\%)

\begin{tabular}{|c|l|c|c|c|}
\hline Tahun & \multicolumn{1}{|c|}{ Jenis kredit } & Kol 1 & Kol 3 & NPL \\
\hline \multirow{2}{*}{2014} & 1. Kredit modal kerja multiguna & 79 & 51 & 43 \\
& 2. Kredit investasi multiguna & 70 & 43 & 41 \\
& 3. Kredit Rekening Koran & 47 & 40 & 35 \\
& 4. Kredit usaha mikro kecil & 45 & 38 & 30 \\
\hline \multirow{2}{*}{2015} & 1. Kredit modal kerja multiguna & 53 & 34 & 20 \\
& 2. Kredit investasi multiguna & 50 & 30 & 17 \\
& 3. Kredit Rekening Koran & 34 & 19 & 22 \\
& 4. Kredit usaha mikro kecil & 30 & 17 & 12 \\
\hline \multirow{2}{*}{016} & 1. Kredit modal kerja multiguna & 65 & 23 & 20 \\
& 2. Kredit investasi multiguna & 59 & 21 & 17 \\
& 3. Kredit Rekening Koran & 46 & 19 & 18 \\
& 4. Kredit usaha mikro kecil & 39 & 20 & 16 \\
\hline
\end{tabular}

Sumber : Bank Nagari Cabang Sijunjung

Data tabel diatas menjukan bahwa kredit modal kerja multiguna dan kredit investasi multiguna mengalami penurunan pada tahun 2014 ini disebabkan karna perusahaan debitur yang mulai berjalan dengan baik dan perusahaannya mulai berkembang maka dari itu NPL nya terjadi penurunan. Sedangkan kredit rekening Koran mengalami fluktuasi ini disebabkan karena kurang berkembangnya suatu usaha seorang debitur. Akan tetapi kredit usaha mikro kecil juga mengalami penurunan pada tahun 2014 ini disebabkan karena meningkatnya / lancarnya suatu usaha debitur, 
sedangkan pada tahun 2015 dan 2016 NPL mengalami penurunan dari semua jenis kreditnya penyebab penurunan ini terjadi karena lancar dan meningkatnya suatu usaha yang sedang dijalankan oleh debitur.

Dalam penyelesaian kredit bermasalah Bank Nagari Cabang Sijunjung melakukan 2 cara yaitu:

1. Secara damaiPenyelesaianm kredit .bermasalah secara damai bisa dilakukan pada debitur yang beritikad baik untuk menyelesaiakan kewajibanya dan cara yang dilakukan diaggap baiak dari pada penyelesaian dengan cara hukum.

Bank Nagari Cabang Sijunjung meberikan keringanan bunga untuk debitur yang termasuk kredit diragukan, macet dan yang telah dihapus bukukan, hal ini diberikan agar debitur bisa mebayar kreditnya walaupun dengan waktu yang kurang lama, dan Bank Nagari Cabang Sijunjung juga akan melakukan pejualan agunan dibawah tangan ini dilakukan agar debitur masih berkesempatan untuk menawarkan/menjual sendiri agunannya.

2.Secara hukum Bank Nagari Cabang Sijunjung melakukan penyelesaian kredit bermasalah secara hukum, hal ini dilakukan apabila dengan penyelesaian secara damai sudah dilakuakn dengan baik namun tidak ada hasil atau debitur tidak menujukan itikad baik dalam menyelesaikan kewajibannya maka pihak Bank Nagari Cabang Sijunjung akan mengirim surat teguran 1x hingga 3x, jika surat teguran tak ada respon dari debitur maka pihak Bank Nagari Cabang Sijunjung akan menyelesaikannya dengan Badan Urusan Piutang Lelang Negara dan Pengadilan Negeri, ini dilakukan untuk melelang aguanan/jaminan debitur untuk mebayar kewajibanya terhadap Bank Nagari Cabang Sijunjung

\section{PENUTUP}

\section{Kesimpulan}

Berdasarkan penelitian dan pembahasan yang telah dilakukan oleh penulis pada Bank Nagari Cabang Sijunjung dan pembahasan hasil penelitian yang telah diuraikan pada bab sebelumnya, maka dapat disimpulkan bahwa :

1. Aktivitas peberian kredit komersil pada Bank Nagari Cabang Sijunjung memiliki langkah - langkah yang terdiri dari permohonan kredit,analisis kredit, penandatangan akad perjanjian kredit, realisasi kredit (pencairan kredit), dan pengawasan kredit yang dilakukan demi kelancaran pengembalian pinjaman sehingga setiap permasalah yang akan timbul dapat segera diketahui dan dapat segera dicari jalan keluarnya.

2. Aktivitas pemberian kredit komersil yang dilaksanakan di Bank Nagari Cabang Sijunjung telah dilakukan dengan baik, yang bisa dilihat dari perkembangan kredit komersil pada tahun 2014 sampai 2016 yang mengalami kenaikan seperti jenis kredit modal kerja multi guna yang meningkat dari tahun ketahun yaitu 33,9\% menjadi 50,7\% dan 90,3\%. Disebabkan karna banyaknya permintaan dari debitur yang ingin mengembangkan usahanya atau memperlancar kegiatan usahanya yang sedang dijalani oleh debitur. 


\section{Saran}

Penulis ingin memberikan saran yang diharapkan dapat bermanfaat bagi Bank Nagari Cabang Sijunjung adalah ketelitian bagi Account Officer dalam melakukan tahap pengecekan untuk menentukan para pemohon kredit yang layak dan tidak layak agar lebih ditingkatkan supaya dapat meminimalisir kredit atau kredit bermasalah. Dan Bank Nagari Cabang Sijunjung lebih bisa meningkatkan aktivitas kredit komersil sehingga kredit komersil bisa disalurkan dengan lebih baik lagi.

\section{DAFTAR PUSTAKA}

Alanshari, F., \& Marlius, D. (2018). Prosedur Pemberian Kredit KPR Pada PT. Bank Tabungan Negara (Persero) TBK Cabang Pembantu Bukittinggi. https://doi.org/10.31227/osf.io/rsfhc

Amelia, L., \& Marlius, D. (2018). Pengendalian Kredit Dalam Upaya Menciptakan Bank Yang Sehat Pada PT. Bank Pembangunan Daerah Sumatera Barat Cabang Utama Padang. https://doi.org/10.31227/osf.io/kpc64

Andriani, B., \& Susanto, R. (2019). Pengawasan Kredit PT. Bank Perkreditan Rakyat (BPR) Ophir Pasaman Barat. https://doi.org/10.31219/osf.io/aunvc

Baiya, \& Fernos, J. (2019). Analisis Faktor-Faktor Penyebab Kredit Macet Pada Bank Nagari Cabang Siteba. https://doi.org/10.31227/osf.io/4xuks

Darmawanto, \& Fernos, J. (2019). Prosedur Pemberian Kredit Pada Bank Nagari Cabang Sijunjung. https://doi.org/10.31227/osf.io/psqfy

Pratama, D., \& Fernos, J. (2019). Prosedur Pelaksanaan Kredit Usaha Rakyat (KUR) Pada PT. Bank Nagari Cabang Padang. https://doi.org/10.31227/osf.io/ag68j

Fahmi Irham, (2014), Manajemen Perkreditan, Bandung, Penerbit: Alfabeta.

Firdaus H. Rahmad dkk, (2011), Manajemen Perkreditan Bank Umum, Bandung, Penerbit: Alfabeta

Firmansyah, A., \& Fernos, J. (2019). Analisis Kredit Bermasalah Dilihat Dari Standar Non Performing Loan (NPL) Pada PT. Bank Perkreditan Rakyat (BPR) Prima Mulia Anugrah Cabang Padang. https://doi.org/10.31227/osf.io/gcj94

Shanjaya, A. R., \& Marlius, D. (2017). Peranan Laporan Keuangan Dalam Kebijaksanaan Pemberian Kredit Kepada Calon Nasabah Pada PT. BPR Batang Kapas. https://doi.org/10.31227/osf.io/uxmg6 
Kasmir, (2012), Dasar-Dasar Perbankan, Jakarta, Penerbit: PT Raja Grafindo Persada.

Malayu S. P. Hasibuan, (2008), Dasar-Dasar Perbankan, Jakarta, Penerbit: PT. Bumi Aksara,

Maryanto Supriyono, (2011), Buku Pintar Perbankan, Yogyakarta, Penerbit: Andi Yogyakarta.

Mudrajat Kuncoro dan Suhardjono, (2010), Manajemen Perbankan, Teori Dan Aplikasi, Edisi Kedua, Yogyakarta, Penerbit: BPFE Yogyakarta.

Orlando, A., \& Susanto, R. (2019). Mekanisme Pencairan Kredit Usaha Rakyat Pada PT. Bank Rakyat Indonesia Unit Lubuk Buaya. https://doi.org/10.31219/osf.io/zuv2y 
Republik Indonesia, Undang Undang Perbankan Nomor 10 Tahun 1998 tanggal 10 Nopember 1998.

Shanjaya, A. R., \& Marlius, D. (2017). Peranan Laporan Keuangan Dalam Kebijaksanaan Pemberian Kredit Kepada Calon Nasabah Pada PT. BPR Batang Kapas. https://doi.org/10.31227/osf.io/uxmg6

Thamrin Abdullah dan Francis Tantri, 2012, Bank dan Lembaga Keuangan, Ed.1-1, Jakarta, Penerbit: Rajawali Pers. 